Article

\title{
Large Neutral Amino Acid Therapy Increases Tyrosine Levels in Adult Patients with Phenylketonuria: A Long-Term Study
}

\author{
Alessandro P. Burlina ${ }^{1}\left(\mathbb{D}\right.$, Chiara Cazzorla $^{2}$, Pamela Massa ${ }^{2}$, Giulia Polo ${ }^{2}\left(0\right.$, Christian Loro ${ }^{2}$, \\ Daniela Gueraldi ${ }^{2}$ and Alberto B. Burlina ${ }^{2, *(D)}$ \\ 1 Neurology Unit, San Bassiano Hospital, 36061 Bassano del Grappa, Italy; alessandro.burlina@aulss7.veneto.it \\ 2 Division of Inherited Metabolic Diseases, Department of Woman's and Child's Health, University Hospital, \\ 35128 Padova, Italy; chiara.cazzorla@aopd.veneto.it (C.C.); pamela.massa@aopd.veneto.it (P.M.); \\ giulia.polo@aopd.veneto.it (G.P.); christian.loro@aopd.veneto.it (C.L.); \\ daniela.gueraldi@aopd.veneto.it (D.G.) \\ * Correspondence: alberto.burlina@unipd.it; Tel.: +39-049-821-3569 (ext. 7462)
}

Received: 10 September 2019; Accepted: 16 October 2019; Published: 21 October 2019

check for updates

\begin{abstract}
The standard treatment for phenylketonuria (PKU) is a lifelong low-phenylalanine (Phe) diet, supplemented with Phe-free protein substitutes; however, adult patients often show poor adherence to therapy. Alternative treatment options include the use of large neutral amino acids (LNAA). The aim of this study was to determine the Phe, tyrosine (Tyr), and Phe/Tyr ratio in a cohort of sub-optimally controlled adult patients with classical PKU treated with a new LNAA formulation. Twelve patients received a Phe-restricted diet plus a slow-release LNAA product taken three times per day, at a dose of $1 \mathrm{~g} / \mathrm{kg}$ body weight (mean $0.8 \pm 0.24 \mathrm{~g} / \mathrm{kg} /$ day), over a 12 -month period. The product is in a microgranulated formulation, which incorporates all amino acids and uses sodium alginate as a hydrophilic carrier to prolong its release. This LNAA formulation provides up to $80 \%$ of the total protein requirement, with the rest of the protein supplied by natural food. Patients had fortnightly measurements of Phe and Tyr levels over a 12-month period after the introduction of LNAA. All patients completed the 12-month treatment period. Overall, adherence to the new LNAA tablets was very good compared with a previous amino acid mixture, for which taste was a major complaint by patients. Phe levels remained unchanged $(p=0.0522)$, and Tyr levels increased $(p=0.0195)$. Consequently, the Phe/Tyr ratio decreased significantly $(p<0.05)$ in the majority of patients treated. In conclusion, LNAA treatment increases Tyr levels in sub-optimally controlled adult PKU patients, while offering the potential to improve their adherence to treatment.
\end{abstract}

Keywords: phenylketonuria; large neutral amino acids; phenylalanine; tyrosine; treatment; blood-brain barrier

\section{Introduction}

Phenylketonuria (PKU, OMIM 261600) is an autosomal recessive genetic disorder caused by mutations of the gene encoding the phenylalanine hydroxylase (PAH, EC1.14.16.1) enzyme [1]. PKU patients are detected by neonatal screening and start a low-phenylalanine (Phe) diet soon after birth [2]. The mainstay of treatment is a lifelong low-Phe diet. The aim of dietary treatment is to prevent excessive Phe accumulation in the blood by strict control of natural protein intake in combination with the administration of a Phe-free/low-Phe protein substitute, usually based on Phe-free l-amino acids [3,4]. The PKU diet allows normal development and Intelligence Quotient (IQ), but blood Phe levels must not exceed the safe age-related range (120-360 $\mu \mathrm{mol} / \mathrm{L}$ for 1-12 years; $120-600 \mu \mathrm{mol} / \mathrm{L}$ for $>13$ years) [2]. However, maintaining these Phe levels is often difficult for adults with PKU [5], 
as a Phe-restricted diet can be perceived as a great burden and a limitation on adult patients' daily life [6]. Despite this, maintenance of good metabolic control is correlated with improved long-term cognitive and behavioral outcomes [7]. Variability of Phe concentration over time due to difficulty in adherence to the prescribed diet may also be a significant negative predictor of long-term outcomes [8].

In our recent findings, which are representative of the whole Italian PKU population, habitual consumption of low-protein foods was reported by $87 \%$ of patients, while the mean use of amino acid mixtures was low: only $18.5 \%$ of patients reported an optimal consumption [9]. The most relevant factors which interfered with adherence to the consumption of amino acid mixtures were the impact of amino acid mixture use in the social context, frequency ( $4-5$ times/day), and its palatability [9-11].

In recent years, alternative or complementary treatments were proposed. New protein substitutes, including large neutral amino acids (LNAA) and glycomacropeptide, and pharmacological treatments, such as sapropterin dihydrochloride (BH4) and phenylalanine ammonia lyase enzyme, were successful in the treatment of adult PKU patients [12-14].

In the pathophysiology of PKU, modification of amino acid transport across the blood-brain barrier (BBB) plays an important role with the increase of brain Phe influx competing with other LNAAs at the same transport level [15]. Therefore, LNAA supplementation may have several important functions: reducing brain Phe concentrations, increasing brain neurotransmitter concentrations, and increasing brain essential amino acid concentrations [16]. LNAA are transported across the blood-brain barrier (BBB) by a family of transport proteins called L-system, which contain LAT1, a catalytic subunit, and a type II glycoprotein subunit called 4F2hc. LAT1-4F2hc is selective for LNAA and is essential for the BBB transport [17]. The role of LNAA and their transport into the brain in PKU patients was reported in 1953 by Christensen, who proposed that high blood concentrations of Phe could interfere with the transport of other LNAAs into the brain [18].

The LNAA transporter facilitates the transport of LNAA across the BBB. Elevated blood levels of Phe is predicted to increase the uptake of Phe at the expense of other LNAAs, resulting in the disruption of brain amino acid homeostasis. In PKU patients, administering large amounts of Phe-free LNAAs competes with Phe and may reduce the influx of Phe into the brain [19].

Nowadays, two different LNAA treatment strategies are reported in the literature: LNAA alone or in combination with a low-Phe diet [16]. All studies that evaluated the use of LNAA in PKU patients were mainly focused on monitoring Phe plasma levels during a very limited time period (less than 6 months) and included mixed cohorts of patients, mostly children and adolescents. In this age range, diet is under the control and/or influence of parents. Nevertheless, a significant reduction of plasma Phe for a short period of time was reported in two studies [20,21], but other authors did not report this effect [19,22-24].

The aim of our study was to evaluate plasma Phe, Tyr, and their ratio in a cohort of sub-optimally controlled classical adult PKU patients treated with a new LNAA formulation combined with a low-Phe diet.

\section{Materials and Methods}

\subsection{Study Population}

In total, 12 adult PKU patients from the Division of Inherited Metabolic Diseases, University Hospital of Padova, Italy, were selected to participate in the study because of their persistently low diet adherence due to their refusal to take supplementation with an amino acid mixture. These patients were already on a Phe-restricted diet and amino acid supplementation covering $80 \%$ of their total protein intake.

Diagnosis of PKU was performed by neonatal screening, and all patients were treated with a Phe-restricted diet from birth. All 12 patients had a PAH genotype and BH4 loading test showing a lack of response to the PAH cofactor sapropterin dihydrochloride. 
Dietary intake was not recorded during the study due to its long treatment period (i.e., 12 months); therefore, detailed information on dietary habits is not available.

The principles of Good Clinical Practice were adhered to throughout the study, in accordance with the Declaration of Helsinki and ICH/GCP. The study was approved by the Ethical Committee of Padua University Hospital, Italy. Written informed consent was obtained from all participants.

\subsection{LNAA Supplementation}

The LNAA formulation used in this study was NeutrAfenil ${ }^{\circledR}$ Micro R (PIAM). This product is registered in Italy for the treatment of PKU under medical prescription, and it is under registration in Turkey and Spain. Because the product does not contain vitamins or minerals, all patients in our study were regularly supplemented with multivitamins and minerals.

The LNAA formulation is a granulation that can be easily swallowed with water or other liquids. The amino acids are incorporated in microgranules that are coated with a methylcellulose film to prevent any unpleasant taste related to the amino acid mixture. The cap of the bottle can be used to measure 17 grams of amino acids.

The most significant characteristics of the LNAA formulation are improved palatability (unflavored taste), its prolonged-release formulation due to sodium alginate as a hydrophilic carrier that provides a physiological absorption similar to that of natural protein, and the high concentration of Tyr in comparison with other available products.

The composition of the LNAA formulation is shown in Table 1

Table 1. Large neutral amino acids (LNAA): nutritional information per $100 \mathrm{~g}$.

\begin{tabular}{lc}
\hline Energy & $\mathbf{1 6 8 6 \mathbf { ~ k J }}$ \\
& $\mathbf{3 9 9} \mathbf{~ k c a l}$ \\
\hline Fat & $5.3 \mathrm{~g}$ \\
of which saturated fat & $5.3 \mathrm{~g}$ \\
\hline Carbohydrates & $12 \mathrm{~g}$ \\
of which sugars & $0 \mathrm{~g}$ \\
\hline Fiber & $5.8 \mathrm{~g}$ \\
Equivalent protein & $70.79 \mathrm{~g}$ \\
Salt & $1.6 \mathrm{~g}$ \\
L-Arginine & 1.92 \\
Aspartate & 4.95 \\
L-phenylalanine & $0 \mathrm{~g}$ \\
L-isoleucine & $10 \mathrm{~g}$ \\
L-histidine & $3.36 \mathrm{~g}$ \\
L-leucine & $12 \mathrm{~g}$ \\
L-lysine & $5.44 \mathrm{~g}$ \\
L-methionine & $2.72 \mathrm{~g}$ \\
L-tyrosine & $24 \mathrm{~g}$ \\
L-threonine & $2.56 \mathrm{~g}$ \\
L-tryptophan & $8 \mathrm{~g}$ \\
L-valine & $10 \mathrm{~g}$ \\
\hline
\end{tabular}

\subsection{Study Design}

The demographic characteristics of the patient population are shown in Table 2. Patient age ranged from 19 to 38 years (mean \pm standard deviation (SD) was $29.6 \pm 6.8$ years), most patients were educated to a high school or University level, and three-quarters of the patients were employed. 
Table 2. Demographic characteristics of all patients.

\begin{tabular}{lll}
\hline \multirow{2}{*}{ Gender } & & $N(\%)$ \\
\hline Age range & Memale & $5(42)$ \\
\hline \multirow{3}{*}{ Marital status } & $19-38$ & $7(58)$ \\
\hline \multirow{4}{*}{ Education level } & Married/with partner & $6(50)$ \\
\cline { 2 - 3 } & Unmarried & $6(50)$ \\
\hline \multirow{5}{*}{ Employment status } & Middle & $1(8)$ \\
\cline { 2 - 3 } & High & $7(58)$ \\
\cline { 2 - 3 } & University & $4(33)$ \\
\hline \multirow{5}{*}{ Leisure time } & Employed & $9(75)$ \\
\cline { 2 - 3 } & Unemployed & $1(8)$ \\
\cline { 2 - 3 } & Student & $2(17)$ \\
\hline & Sport & $2(25)$ \\
\cline { 2 - 3 } & Social activity & $2(17)$ \\
\cline { 2 - 3 } & Art, museum, exhibitions & $5(42)$ \\
\cline { 2 - 3 } & Not specified & \\
\hline
\end{tabular}

Abbreviations: LNAA, large neutral amino acids; $N$, number.

The LNAA supplement was taken three times per day over a 12-month period (breakfast, lunch, and dinner), at a dose of $1 \mathrm{~g} / \mathrm{kg}$ body weight. No other amino acid mixture was given to the patients and no changes were made to their low-Phe diet.

Patients collected fasting blood spots at home every two weeks in the morning before taking LNAAs. Measurements of Phe and Tyr levels were done on these dried blood spots (DBS) using liquid chromatography/tandem mass spectrometry, and the Phe/Tyr ratio was calculated. The consumption of LNAA was calculated by the dietitian every six months. All patients stated that, due to their commitments, they generally had lunch or dinner out of the home, with a high intake of Phe (3-4 times the prescribed value).

\subsection{Statistical Analysis}

The Wilcoxon paired sample T-test was adopted to compare data sets acquired from the patients before and after the start of LNAA therapy. A $p$-value of $<0.05$ was considered significant. Categorical variables are expressed as $N(\%)$, and quantitative variables are expressed as mean $\pm \mathrm{SD}$.

\section{Results}

Patient nutritional data prior to and after LNAA were introduced, including the total protein intake, medical foods intake, and Phe and Tyr intake, are summarized in Table 3. In general, the nutrient profile of LNAA treatment was constant during the 12-month period, whereas the amino acid mixtures-medical foods (AAM-MF) intake was often refused by the patients. The total Tyr intake $(\mathrm{g} /$ day and $\mathrm{mg} / \mathrm{kg})$ in LNAA was significantly higher than in the standard AAM-MF ( $p=0.008$ and $p=0.0039$, respectively); no significant differences were identified for the other components. 
Table 3. Composition of standard amino acid mixtures compared with LNAA.

\begin{tabular}{lcccc}
\hline & \multicolumn{2}{c}{ AAM-MF } & \multicolumn{2}{c}{ LNAA-MF } \\
\cline { 2 - 5 } & Mean \pm SD & Median & Mean \pm SD & Median \\
\hline Total proteins (g/day) & $72 \pm 11$ & 70 & $63 \pm 13.45$ & 59 \\
Total proteins (g/kg/day) & $1 \pm 0.23$ & 1.13 & $0.8 \pm 0.24$ & 0.75 \\
MF (g/day) & $51 \pm 7.36$ & 52 & $42 \pm 9.78$ & 38 \\
MF (g/kg/day) & $0.7 \pm 0.23$ & 0.8 & $0.5 \pm 0.21$ & 0.4 \\
Phe intake (mg/day) & $834 \pm 455.41$ & 700 & $709 \pm 199.91$ & 700 \\
Phe intake (mg/kg) & $12 \pm 4.81$ & 10.3 & $10 \pm 1.8$ & 10.2 \\
Tyr intake (g/day) & $4.8 \pm 0.72$ & 4.6 & $6.6 \pm 0.61$ & 6.5 \\
Tyr intake (mg/kg) & $73 \pm 21.54$ & 74.7 & $100 \pm 26.1$ & 103.7 \\
\hline
\end{tabular}

Abbreviations: AAM, amino acid mixtures; LNAA, large neutral amino acids; MF, medical foods.

In the 12-month period prior to the introduction of LNAA, the mean \pm SD Phe and Tyr values ranged from $628 \pm 148$ to $1033 \pm 198 \mu \mathrm{mol} / \mathrm{L}$ and from $32 \pm 7$ to $87 \pm 35 \mu \mathrm{mol} / \mathrm{L}$, respectively, while the mean \pm SD Phe/Tyr ratio ranged from $9.7 \pm 2.2$ to $19.9 \pm 2.8 \mu \mathrm{mol} / \mathrm{L}$, and the DBS frequency ranged from 5 to 38 (median $=19$ ): 3 patients $(25 \%)$ sent more than 24 DBS samples. Phe and Tyr values, Phe/Tyr ratio, and DBS frequency are shown for each patient in Table 4 and are summarized for the overall population in Table 5. The molecular analysis of each patient is shown in Table 4.

All 12 patients completed the 12-month trial. At baseline and at the end of the study, patients had a mean \pm SD weight of $70.0 \pm 18 \mathrm{~kg}$ and $70.4 \pm 18 \mathrm{~kg}$, respectively, and a mean \pm SD BMI index of $24.80 \pm 4.83$ and $24.92 \pm 5.11$, respectively. Neither weight nor BMI were significantly different when compared prior to and after the introduction of LNAA ( $p=0.57$ and $p=0.95$, respectively).

Adherence to LNAA supplementation was very good.

Tables 4 and 5 also show the mean values of Phe, Tyr, and mean Phe/Tyr ratio and frequency of DBS measurements for each patient and for the overall population, respectively, over the 12-month treatment period. Overall, the mean \pm SD Phe and Tyr values ranged from $736 \pm 93$ to $1269 \pm 265 \mu \mathrm{mol} / \mathrm{L}$ and from $59 \pm 15$ to $108 \pm 35 \mu \mathrm{mol} / \mathrm{L}$, respectively, while the mean \pm SD Phe/Tyr ratio ranged from $8 \pm 1.4$ to $20.6 \pm 7.6 \mu \mathrm{mol} / \mathrm{L}$. The frequency of DBS ranged from 14 to 39 (median $=23.5$ ) over the 12 -month treatment period: 7 patients $(58 \%)$ sent more than 24 DBS samples. The statistical difference in the DBS frequency pre- and post-LNAA introduction was significant $(p=0.0088)$ (Table 5).

For most patients, mean Phe levels were similar before and after the 12-month treatment period with LNAA (Figure 1), whereas Tyr levels increased significantly in 11 out of 12 patients (92\%) (mean $75 \mu \mathrm{mol} / \mathrm{L} \pm 16 \mu \mathrm{mol} / \mathrm{L} ; p=0.0195)$ (Figure 2). Compared with before the introduction of LNAA, the mean Phe/Tyr ratio decreased significantly in 10 out of 12 patients (83\%) (mean $12 \mu \mathrm{mol} / \mathrm{L} \pm 3 \mu \mathrm{mol} / \mathrm{L} ; p<0.05)$ after 12-months of treatment with LNAA; in 2 patients, the Phe/Tyr ratio showed a small increase (mean $17 \mu \mathrm{mol} / \mathrm{L} \pm 5 \mu \mathrm{mol} / \mathrm{L} ; p<0.16$ ) (Figure 3). 
Table 4. Molecular analysis of each patient and the mean (SD) values of Phe, Tyr, Phe/Tyr ratio, and DBS frequency over the 12-month period prior to the introduction of LNAA and over the 12-month LNAA treatment period.

\begin{tabular}{|c|c|c|c|c|c|c|c|c|c|}
\hline \multirow[b]{2}{*}{ Patient } & \multirow[b]{2}{*}{ Molecular Analysis } & \multicolumn{4}{|c|}{ 12-month Period Prior to LNAA } & \multicolumn{4}{|c|}{ 12-month LNAA Treatment Period } \\
\hline & & $\begin{array}{c}\text { Mean Phe } \\
\text { Values }^{\text {a }} \text { (SD) }\end{array}$ & $\begin{array}{c}\text { Mean Tyr } \\
\text { Values }^{\text {a }} \text { (SD) }\end{array}$ & $\begin{array}{l}\text { Mean Phe/Tyr } \\
\text { Values a (SD) }\end{array}$ & $\begin{array}{c}\text { DBS } \\
\text { Frequency }\end{array}$ & $\begin{array}{c}\text { Mean Phe } \\
\text { Values }^{\text {a }} \text { (SD) }\end{array}$ & $\begin{array}{c}\text { Mean Tyr } \\
\text { Values }^{\text {a }} \text { (SD) }\end{array}$ & $\begin{array}{l}\text { Mean Phe/Tyr } \\
\text { Values a (SD) }\end{array}$ & $\begin{array}{c}\text { DBS } \\
\text { Frequency }\end{array}$ \\
\hline 1 & c. $473 \mathrm{G}>\mathrm{A} / \mathrm{c} .1315+1 \mathrm{G}>\mathrm{A}$ & $790(80)$ & $47(8)$ & $17.2(2.5)$ & 8 & $825(114)$ & $68(10)$ & $12.4(2.4)$ & 17 \\
\hline 2 & c. $473 \mathrm{G}>\mathrm{A} / \mathrm{c} .526 \mathrm{C}>\mathrm{T}$ & $1033(198)$ & $54(10)$ & $19.5(4.4)$ & 5 & $1269(265)$ & $65(14)$ & $20.6(7.6)$ & 14 \\
\hline 3 & c. $473 \mathrm{G}>\mathrm{A} / \mathrm{c} .473 \mathrm{G}>\mathrm{A}$ & $983(142)$ & $32(7)$ & $31.5(7.3)$ & 10 & $907(166)$ & $60(8)$ & $15.4(3)$ & 20 \\
\hline 4 & c. $842+3 G>C$ in heterozygosis & $790(118)$ & $83(14)$ & $9.7(2.2)$ & 18 & $769(144)$ & $98(18)$ & $8(1.4)$ & 34 \\
\hline 5 & c. $47 \_48 \mathrm{delCT} / \mathrm{c} .1315+2 \mathrm{~T}>\mathrm{C}$ & $838(179)$ & $57(12)$ & $15.7(6.6)$ & 20 & 889 (149) & 79 (19) & $11.7(2.7)$ & 24 \\
\hline 6 & c. $842 \mathrm{C}>\mathrm{T} / \mathrm{c} .1315+1 \mathrm{G}>\mathrm{A}$ & $880(160)$ & $49(11)$ & $18.3(4)$ & 38 & $975(148)$ & $68(29)$ & $16(5)$ & 39 \\
\hline 7 & c. $842 \mathrm{C}>\mathrm{T} / \mathrm{c} .1315+1 \mathrm{G}>\mathrm{A}$ & $779(108)$ & $87(35)$ & $10.6(5)$ & 25 & $736(93)$ & $86(41)$ & $10.5(4.9)$ & 27 \\
\hline 8 & c. $842 \mathrm{C}>\mathrm{T} / \mathrm{c} .1315+1 \mathrm{G}>\mathrm{A}$ & $628(148)$ & $50(13)$ & $13(5.2)$ & 26 & 790 (147) & 59 (15) & $14(4.5)$ & 29 \\
\hline 9 & c. $1222 \mathrm{C}>\mathrm{T} / \mathrm{c} \cdot 1315+1 \mathrm{G}>\mathrm{A}$ & $808(135)$ & $59(7)$ & $19.9(2.8)$ & 12 & $925(139)$ & $79(13)$ & $11.9(1.8)$ & 18 \\
\hline 10 & c. $782 \mathrm{G}>\mathrm{A} / \mathrm{c} .782 \mathrm{G}>\mathrm{A}$ & $842(94)$ & $75(12)$ & $11.5(2.3)$ & 23 & $879(91)$ & $108(35)$ & $8.5(1.9)$ & 36 \\
\hline 11 & c. $782 \mathrm{G}>\mathrm{A} / \mathrm{c} .1066-11 \mathrm{G}>\mathrm{A}$ & $765(234)$ & $58(11)$ & $13.4(3.9)$ & 23 & $760(124)$ & $60(11)$ & $13(2.7)$ & 24 \\
\hline 12 & c. $1222 \mathrm{C}>\mathrm{T} /$ macro deletion in exon 3 & $823(117)$ & $53(19)$ & $16.9(5)$ & 18 & $1000(163)$ & $68(17)$ & $15.2(3.7)$ & 15 \\
\hline
\end{tabular}

Abbreviations: DBS, dried blood spots; Phe, phenylalanine; SD, standard deviation; Tyr, tyrosine. ${ }^{\text {a }}$ Expressed in $\mu \mathrm{mol} / \mathrm{L}$. 
Table 5. Phe, Tyr, Phe/Tyr ratio, and DBS frequency over the 12-month period prior to the introduction of LNAA and over the 12-month LNAA treatment period for the overall patient population.

\begin{tabular}{cccc}
\hline Overall Patient Population & $\begin{array}{c}\text { 12-Month Period } \\
\text { Prior to LNAA }\end{array}$ & $\begin{array}{c}\text { 12-Month LNAA } \\
\text { Treatment Period }\end{array}$ & $p$-Value \\
\hline Phe $\mu \mathrm{mol} / \mathrm{L}$, mean (SD) & $752(143)$ & $894(145)$ & 0.0522 \\
\hline Tyr $\mu \mathrm{mol} / \mathrm{L}$, mean (SD) & $59(13)$ & $75(16)$ & 0.0195 \\
\hline Phe/Tyr ratio $\mu \mathrm{mol} / \mathrm{L}$, mean $(\mathrm{SD})$ & $16(4)$ & $13(3)$ & 0.049 \\
\hline DBS frequency & $19(9)$ & $25(8)$ & 0.0088 \\
\hline
\end{tabular}

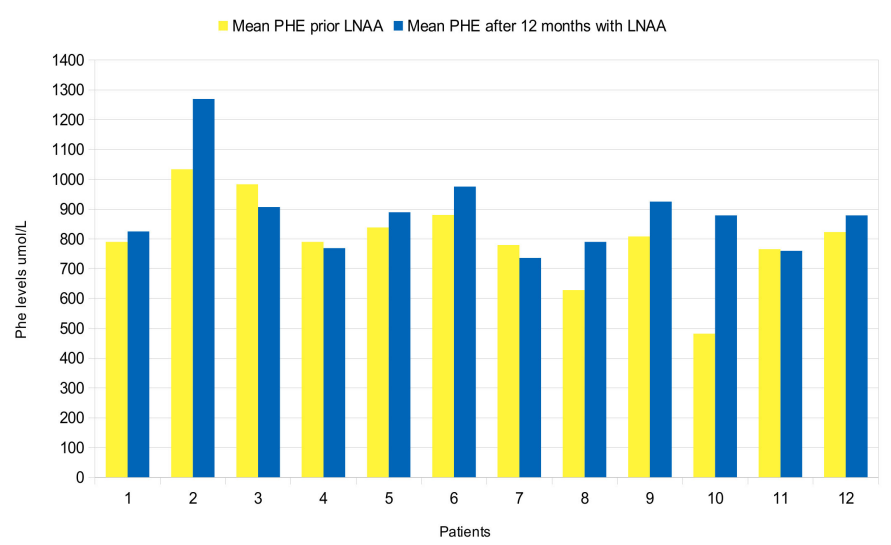

Figure 1. Mean Phe levels 12 months prior and after LNAA introduction for each patient.

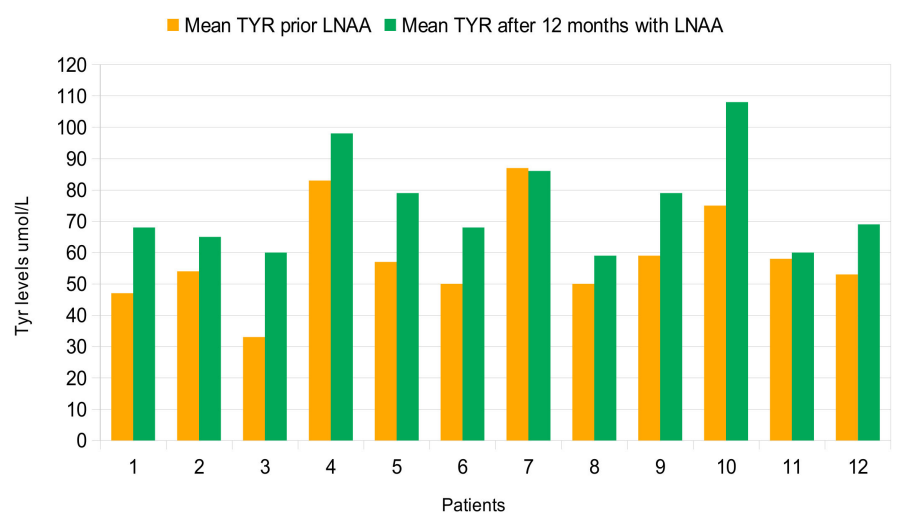

Figure 2. Mean Tyr levels 12 months prior and after LNAA introduction for each patient.

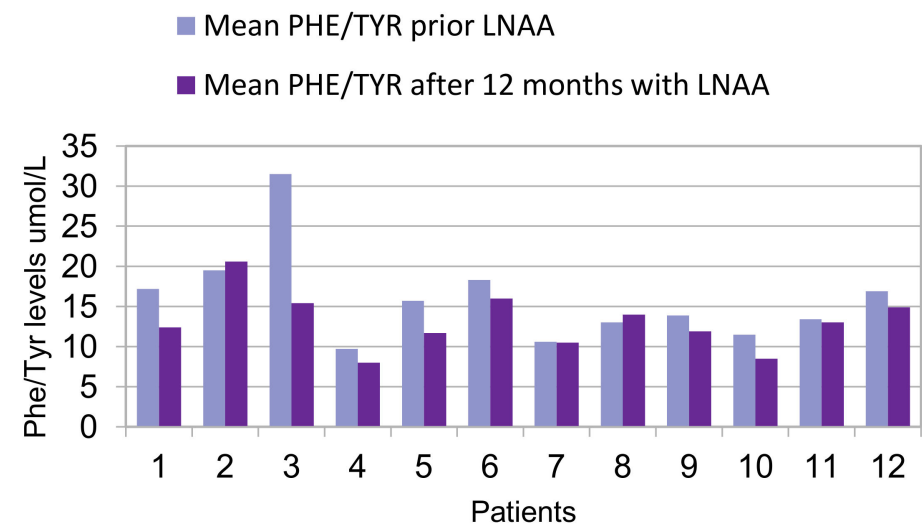

Figure 3. Mean Phe/Tyr ratio 12 months prior and after LNAA introduction for each patient. 
We also report data which illustrates the level of Phe and Tyr at baseline, after 6 months (short term), and after 12 months (long term) of LNAA treatment for each patient (Figures 4 and 5, respectively) and for the overall population (Table 6).

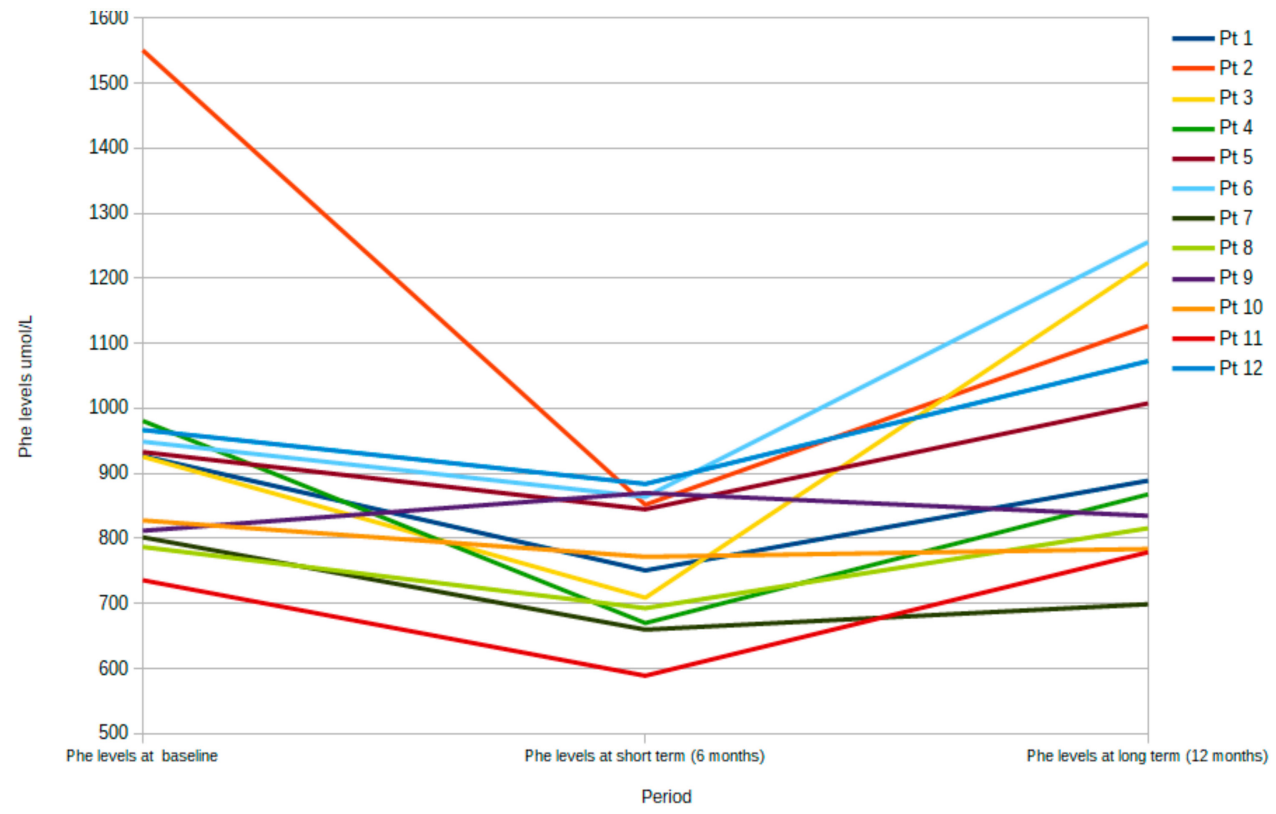

Figure 4. Phe level at each time point: baseline, after 6 months (short term) and 12 months (long term) of LNAA treatment for each patient.

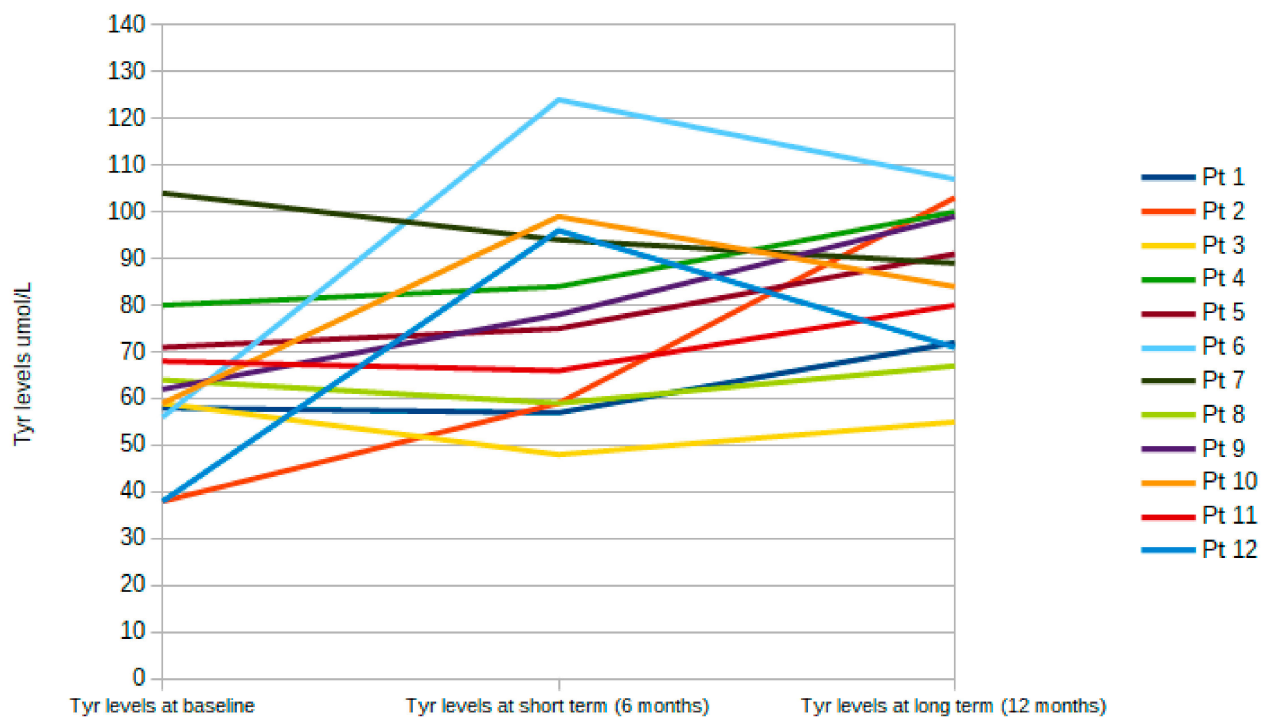

Figure 5. Tyr level at each time point: baseline, after 6 months (short term) and 12 months (long term) of LNAA treatment for each patient. 
Table 6. Phe and Tyr values at baseline, 6 months and 12 months after the LNAA treatment period for the overall patient population.

\begin{tabular}{cccc}
\hline $\begin{array}{c}\text { Overall Patient } \\
\text { Population }\end{array}$ & $\begin{array}{c}\text { 12-Month Period Prior } \\
\text { to LNAA }\end{array}$ & $\begin{array}{c}\text { 6-Month LNAA } \\
\text { Treatment Period }\end{array}$ & $\begin{array}{c}\text { 12-Month LNAA } \\
\text { Treatment Period }\end{array}$ \\
\hline Phe $\mu \mathrm{mol} / \mathrm{L}$, mean (SD) & $752(143)$ & $645(101)^{*}$ & $894(145)^{* *}$ \\
\hline Tyr $\mu \mathrm{mol} / \mathrm{L}$, mean (SD) & $59(13)$ & $65(16)^{*}$ & $75(16)^{* *}$ \\
\hline \multicolumn{2}{c}{$p$-value: Phe $p=0.00458$, Tyr $p=0.324 .{ }^{* *} p$-value: Phe $p=0.00374$, Tyr $p=0.1400}$.
\end{tabular}

Compared with baseline, Phe values decreased significantly in the first six months (short-term period) ( $p=0.00458)$, but then increased significantly $(p=0.0522)$ in the last six-month treatment period with LNAA (Figure 4 and Table 5). Although dietary intake was not recorded during the study, it is likely that a stricter diet regimen over the initial six-month treatment period resulted in the decrease in Phe levels at six months, whereas patients may have relaxed their dietary restrictions, causing Phe values to increase at 12 months. On the other hand, Tyr levels tended to be stable over time, with no significant increase over the short-term period (baseline to six months; $p=0.324$ ) or from 6 to 12 months $(p=0.1400)$ (Figure 5), suggesting that consumption of the new LNAA formulation was consistent.

\section{Discussion}

In this study, blood Tyr levels were significantly elevated in the patient cohort for the entire duration of the study. The mean percentage variation increased after 12 months of treatment, and the difference in Tyr levels compared with baseline was statistically significant. Even in the short-term, Tyr values showed an increase, which was also confirmed in the long-term (12 month), with an increase in $67 \%$ of patients. This increase also reflects the high amount of Tyr present in the LNAA formulation in comparison with other available products. Changes of Tyr levels were also confirmed by the decrease in Phe/Tyr ratio during all periods of the study.

In our study, mean blood Phe levels did not change significantly in the 12 months before starting LNAA therapy compared with the 12-month period after the initiation of LNAA therapy. Indeed, patients still showed poor control over Phe levels. These data support previous studies [24] that did not show any change in blood Phe levels after LNAA administration. In a previous study conducted in a different cohort of PKU patients, we observed a reduction of plasma Phe concentration after one week of treatment with a different LNAA product [20].

In our study, we confirmed these results over a short-term period, but a decrease of Phe values was not confirmed over a long-term period (12 months). Indeed, at the end of this study, Phe levels returned to high levels in $75 \%$ of patients.

Blood Phe concentration remained unchanged after one and six months of LNAA supplementation in a small cohort of six patients with classical PKU [23]. Nonetheless, an increase in blood Tyr and tryptophan (Trp) levels was observed, while proton magnetic resonance spectroscopy detected a decrease in brain Phe levels. Despite the correlation between the use of LNAA and brain Phe concentrations, blood Phe levels do not appear to be influenced by ingestion of the LNAA mixture [23].

In a previous study, which focused on adult Italian patients, we showed that dietary adherence was poor, with reduced daily use of amino acid supplements ( $<4-5$ times/day in $82 \%$ patients) [9]. The survey also showed that the mean daily use of amino acid mixtures was low due to patient embarrassment in consuming mixtures when out of home or while traveling, the palatability of the mixture, and the number of administrations required.

The use of LNAAs in the treatment of patients with PKU was suggested as early as 1948 and offers an alternative complementary treatment option; however, the optimal composition of LNAA is still unknown [25].

Studies that have evaluated LNAA in PKU patients [26,27] are relevant; however, they failed to show any clear advantage in terms of a reduction in brain Phe concentrations. A four-week study 
performed with 16 classical PKU patients on a strict daily food diary identified a trend toward lower plasma Phe levels with LNAA supplementation, suggesting that LNAA supplementation may be beneficial in patients who are unable to comply with PKU medical products [28]. The authors suggested that the reduction of plasma Phe levels with LNAA supplementation may be due to competition with Phe at the level of transport across the gut, but without direct measurement of brain/gut levels, these findings are speculative.

In 2006, Matalon and colleagues evaluated a new formulation of LNAA (with administration of 0.5 to $1 \mathrm{~g} / \mathrm{kg} /$ day) and reported that blood Phe concentrations decreased after one week without any change in dietary practice [21]. A following study showed a significant reduction of Phe blood concentrations (average reduction of 39\%) in all 20 patients treated with LNAA supplements compared with a decline of $5.4 \%$ in the placebo group [20].

The most recent report on the use of LNAA demonstrated a positive correlation between blood Phe reduction and LNAA intake in 12 PKU children after four weeks of treatment [22]. Notably, patients who had a smaller reduction in Phe levels were adolescents. The authors hypothesized that younger children were able to follow their diet more strictly because of their parents' supervision, whereas parental supervision was less effective over adolescents [22].

Data on brain Phe levels in patients treated with LNAA are scarce. Pietz et al. showed that LNAA had the ability to block Phe transport into the brain [19]. In this study, they used an oral purified L-Phe dose, with or without LNAA, and measured the influx of Phe into the brain, using proton magnetic resonance spectroscopy. They showed that cerebral Phe concentrations remained unchanged or decreased during the concomitant LNAA consumption, even if the plasma Phe levels increased.

In animal experiments using PKU mice on a normal diet supplemented with LNAA, van Vliet and colleagues showed significantly reduced brain Phe concentration and increased brain serotonin and norepinephrine, but no significant changes in dopamine concentration [15]. The same authors also showed that, in PKU mice, LNAA were as equally effective as a severe Phe-restricted diet in restoring brain monoamine concentrations, thus indicating that this therapy could be a promising alternative strategy for treating adult PKU patients who are unable adhere to a severe Phe-restricted diet [29]. It is noteworthy that the accumulation of Phe even in early treated patients can lead to cerebrospinal fluid neurotransmitter deficits, with a reduction of homovanillic acid and 5-hydroxyindoloacetic acid [30,31]. Therefore, the possibility of modifying the therapeutic approach by reducing the flux of Phe into the brain, with the mechanism of LNAA competition, could offer a major benefit in the treatment of the disease.

The change in LNAA levels detected in plasma and the brain reflects the different distribution of LNAA in plasma, in the neurovascular unit, and the actions of the specific transporter systems across the BBB. The PAH, which converts Phe into Tyr, is not expressed in the brain. Experimental models showed that Tyr is the LNAA with the most consistent correlation between serum ratio and brain tissue levels [32]. Indeed, all Tyr available to the brain should be transported from the blood. On the other hand, the kinetics of Phe are unique, with the highest affinity for BBB transport in the rat brain [33].

The complexity of the neurovascular unit, which comprises the BBB endothelium, the astrocytes, and neurons, also makes any direct comparison between LNAA data achieved from experimental models with those of the human brain difficult [34].

Most patients in our cohort showed nonsignificant biochemical changes (blood Phe levels) at the end of the LNAA treatment period, which is contradictory to some of the previously published studies. However, previous studies were carried out over very short time periods (less than 12 months), whereas patients in the current study were treated with LNAA for a 12-month period. Indeed, in the short term (less than 6 months), a decrease in Phe levels was detected, but Phe levels returned to baseline levels for the majority of patients by the end of the 12-month treatment period (Figure 4).

Another possible contributing factor to the nonsignificant reduction of Phe levels is the age of the patients. In our cohort, the patients were all adults, whereas, in the Concolino study, they were pediatric patients, with a better therapy adherence [22]. 
Limited data are available regarding Tyr values and Phe/Tyr ratio in patients on LNAA supplementation. The LNAA product used in the current study is very rich in Tyr and Trp in comparison with other products on the market and offers a new extended-release formulation. Both these characteristics can help avoid fluctuation of blood Phe in adults. Phe fluctuations were already suggested as a major source of neurotransmitter perturbation, with subsequent behavioral complications for PKU patients [35]. More recently, an in silico model, simulating the PKU condition, suggested that LNAA supplementation could contribute to maintaining Phe at normal physiologic levels, avoiding inappropriate Phe distribution inside the neurovascular unit [36].

Moreover, high levels of Tyr may promote an increased brain monoaminergic neurotransmitter concentration [37]. Three mechanisms driving the improvement observed with LNAA administration were confirmed in a murine PKU model: LNAA supplementation reduced brain Phe levels, increased brain levels of non-Phe LNAA, and increased neurotransmitter levels [15].

Results from our study suggest that the period of biochemical and clinical follow-up should be increased in comparison with what was known from previous studies. It is possible that a follow-up of 12 months is still not long enough for a chronic condition like PKU. At present, we are continuing to monitor the patients receiving LNAA treatment.

\section{Limitations}

There are limitations within the current study. Firstly, the results of our study are related to a relatively small group of noncompliant adult PKU patients over a long period of time. It is difficult to compare our observational study with other published studies in patients (children and adults combined) conducted over a short period of time. Although some findings may be a consequence of bias and lack of an optimal composition of LNAA, a follow-up study with an increased number of noncompliant patients should be performed before concrete conclusions can be drawn.

Secondly, food intake and compliance were not regularly recorded and obtained through self-reporting. The authors believe that this closely reflects the real life of adult PKU patients; however, patient-centered data collection presents opportunities for misreporting. The ability to conduct a research study is particularly difficult when the patients are predominantly noncompliant PKU and are disengaged from active metabolic follow-up, highlighting the challenges in their inclusion in relatively complicated research procedures. This has done recruitment particularly difficult and the design of a randomized control trial study complex, as recently reported by Green et al. [38].

Thirdly, the plasma Phe, Tyr, and their relative ratio are clinically effective biomarkers for the follow up of the disease, but due to the lack of standardization of blood sampling obtained through self-completed blood samples, caution should be taken when extrapolating the results of this study.

\section{Conclusions}

In conclusion, LNAA supplementation to a low-protein diet should be considered in adult PKU patients who refuse amino acid mixtures. The use of a different therapeutic option, such as LNAA with its tasteless formulation, showed two major results: the increase of blood Tyr levels and the improvement of patient adherence to medication. Further studies are needed to assess the nutritional intake and metabolic status of PKU patients using LNAA for longer periods of time (i.e., 24-36 months).

Author Contributions: Conception and design of the study, A.B.B. and A.P.B.; Collection and organization of biochemical and clinical information, C.C., P.M., C.L., D.G., G.P., and A.B.B.; Writing of draft manuscript, A.B.B. and A.P.B.; Revision and preparation of final manuscript, A.B.B., P.M., and A.P.B.; overall supervision of the study, A.B.B. and A.P.B. All authors read and approved the content of the final manuscript.

Funding: This research did not receive any specific grant from funding agencies in the public, commercial, or not-for-profit sectors. Medical writing assistance was funded by PIAM, Italy.

Acknowledgments: The authors would like to thank the patients and their families involved in the study. We thank Cometa A.S.M.M.E.-Associazione Studio Malattie Metaboliche Ereditarie-ONLUs for supporting patients with PKU. The authors would like to thank Carmen Innes and Melanie Gatt, PhD, independent medical 
writers on behalf of Springer Healthcare Italy, for editorial assistance. The authors also thank Alessia Buratin for assistance with the statistical analysis.

Conflicts of Interest: Alberto Burlina has received advisory board honoraria, speaker fees, and travel support from Biomarin, Nutricia, APR, PIAM Farmaceutici, Sanofi Genzyme, Takeda Shire, and Orphan Recordati. Alessandro P. Burlina has received advisory board honoraria, speaker fees, and travel support from Amicus Therapeutics, Biomarin, Freeline Therapeutics, Nutricia, PIAM Farmaceutici, and Sanofi Genzyme. The other authors declare no conflict of interest.

\section{References}

1. Blau, N.; van Spronsen, F.J.; Levy, H.L. Phenylketonuria. Lancet 2010, 376, 1417-1427. [CrossRef]

2. Van Spronsen, F.J.; van Wegberg, A.M.; Ahring, K.; Belanger-Quintana, A.; Blau, N.; Bosch, A.M.; Burlina, A.; Campistol, J.; Feillet, F.; Gizewska, M.; et al. Key European guidelines for the diagnosis and management of patients with phenylketonuria. Lancet Diabetes Endocrinol. 2017, 5, 743-756. [CrossRef]

3. Camp, K.M.; Parisi, M.A.; Acosta, P.B.; Berry, G.T.; Bilder, D.A.; Blau, N.; Bodamer, O.A.; Brosco, J.P.; Brown, C.S.; Burlina, A.B.; et al. Phenylketonuria Scientific Review Conference: State of the science and future research needs. Mol. Genet. Metab. 2014, 112, 87-122. [CrossRef] [PubMed]

4. Van Wegberg, A.M.J.; MacDonald, A.; Ahring, K.; Belanger-Quintana, A.; Blau, N.; Bosch, A.M.; Burlina, A.; Campistol, J.; Feillet, F.; Gizewska, M.; et al. The complete European guidelines on phenylketonuria: Diagnosis and treatment. Orphanet J. Rare Dis. 2017, 12, 162. [CrossRef] [PubMed]

5. MacDonald, A. Diet and compliance in phenylketonuria. Eur. J. Pediatr. 2000, 159 (Suppl. 2), S136-S141. [CrossRef]

6. Cazzorla, C.; Del Rizzo, M.; Burgard, P.; Zanco, C.; Bordugo, A.; Burlina, A.B.; Burlina, A.P. Application of the WHOQOL-100 for the assessment of quality of life of adult patients with inherited metabolic diseases. Mol. Genet. Metab. 2012, 106, 25-30. [CrossRef] [PubMed]

7. Bilder, D.A.; Burton, B.K.; Coon, H.; Leviton, L.; Ashworth, J.; Lundy, B.D.; Vespa, H.; Bakian, A.V.; Longo, N. Psychiatric symptoms in adults with phenylketonuria. Mol. Genet. Metab. 2013, 108, 155-160. [CrossRef]

8. MacDonald, A.; Gokmen-Ozel, H.; van Rijn, M.; Burgard, P. The reality of dietary compliance in the management of phenylketonuria. J. Inherit. Metab. Dis. 2010, 33, 665-670. [CrossRef]

9. Cazzorla, C.; Bensi, G.; Biasucci, G.; Leuzzi, V.; Manti, F.; Musumeci, A.; Papadia, F.; Stoppioni, V.; Tummolo, A.; Vendemiale, M.; et al. Living with phenylketonuria in adulthood: The pku attitude study. Mol. Genet. Metab. Rep. 2018, 16, 39-45. [CrossRef]

10. Ford, S.; O'Driscoll, M.; MacDonald, A. Living with Phenylketonuria: Lessons from the PKU community. Mol. Genet. Metab. Rep. 2018, 17, 57-63. [CrossRef]

11. Jurecki, E.R.; Cederbaum, S.; Kopesky, J.; Perry, K.; Rohr, F.; Sanchez-Valle, A.; Viau, K.S.; Sheinin, M.Y.; Cohen-Pfeffer, J.L. Adherence to clinic recommendations among patients with phenylketonuria in the United States. Mol. Genet. Metab. 2017, 120, 190-197. [CrossRef] [PubMed]

12. Longo, N.; Dimmock, D.; Levy, H.; Viau, K.; Bausell, H.; Bilder, D.A.; Burton, B.; Gross, C.; Northrup, H.; Rohr, F.; et al. Evidence-and consensus-based recommendations for the use of pegvaliase in adults with phenylketonuria. Genet. Med. 2019, 21, 1851-1867. [CrossRef] [PubMed]

13. Muntau, A.C.; Roschinger, W.; Habich, M.; Demmelmair, H.; Hoffmann, B.; Sommerhoff, C.P.; Roscher, A.A. Tetrahydrobiopterin as an alternative treatment for mild phenylketonuria. N. Engl. J. Med. 2002, 347, 2122-2132. [CrossRef] [PubMed]

14. Pena, M.J.; Pinto, A.; Daly, A.; MacDonald, A.; Azevedo, L.; Rocha, J.C.; Borges, N. The use of glycomacropeptide in patients with phenylketonuria: A systematic review and meta-analysis. Nutrients 2018, 10, 1794. [CrossRef] [PubMed]

15. Van Vliet, D.; Bruinenberg, V.M.; Mazzola, P.N.; van Faassen, M.H.; de Blaauw, P.; Kema, I.P.; Heiner-Fokkema, M.R.; van Anholt, R.D.; van der Zee, E.A.; van Spronsen, F.J. Large neutral amino acid supplementation exerts its effect through three synergistic mechanisms: Proof of principle in phenylketonuria mice. PLoS ONE 2015, 10, e0143833. [CrossRef] [PubMed]

16. Van Spronsen, F.J.; de Groot, M.J.; Hoeksma, M.; Reijngoud, D.J.; van Rijn, M. Large neutral amino acids in the treatment of PKU: From theory to practice. J. Inherit. Metab. Dis. 2010, 33, 671-676. [CrossRef] 
17. Kanai, Y.; Segawa, H.; Miyamoto, K.; Uchino, H.; Takeda, E.; Endou, H. Expression cloning and characterization of a transporter for large neutral amino acids activated by the heavy chain of 4F2 antigen (CD98). J. Biol. Chem. 1998, 273, 23629-23632. [CrossRef]

18. Christensen, H.N. Metabolism of amino acids and proteins. Annu. Rev. Biochem. 1953, 22, 233-260. [CrossRef]

19. Pietz, J.; Kreis, R.; Rupp, A.; Mayatepek, E.; Rating, D.; Boesch, C.; Bremer, H.J. Large neutral amino acids block phenylalanine transport into brain tissue in patients with phenylketonuria. J. Clin. Investig. 1999, 103, 1169-1178. [CrossRef]

20. Matalon, R.; Michals-Matalon, K.; Bhatia, G.; Burlina, A.B.; Burlina, A.P.; Braga, C.; Fiori, L.; Giovannini, M.; Grechanina, E.; Novikov, P.; et al. Double blind placebo control trial of large neutral amino acids in treatment of PKU: Effect on blood phenylalanine. J. Inherit. Metab. Dis. 2007, 30, 153-158. [CrossRef]

21. Matalon, R.; Michals-Matalon, K.; Bhatia, G.; Grechanina, E.; Novikov, P.; McDonald, J.D.; Grady, J.; Tyring, S.K.; Guttler, F. Large neutral amino acids in the treatment of phenylketonuria (PKU). J. Inherit. Metab. Dis. 2006, 29, 732-738. [CrossRef] [PubMed]

22. Concolino, D.; Mascaro, I.; Moricca, M.T.; Bonapace, G.; Matalon, K.; Trapasso, J.; Radhakrishnan, G.; Ferrara, C.; Matalon, R.; Strisciuglio, P. Long-term treatment of phenylketonuria with a new medical food containing large neutral amino acids. Eur. J. Clin. Nutr. 2017, 71, 51-55. [CrossRef] [PubMed]

23. Koch, R.; Moseley, K.D.; Yano, S.; Nelson, M., Jr.; Moats, R.A. Large neutral amino acid therapy and phenylketonuria: A promising approach to treatment. Mol. Genet. Metab. 2003, 79, 110-113. [CrossRef]

24. Yano, S.; Moseley, K.; Azen, C. Large neutral amino acid supplementation increases melatonin synthesis in phenylketonuria: A new biomarker. J. Pediatr. 2013, 162, 999-1003. [CrossRef]

25. Rocha, J.C.; MacDonald, A. Dietary intervention in the management of phenylketonuria: Current perspectives. Pediatric Health Med. Ther. 2016, 7, 155-163. [CrossRef]

26. Dotremont, H.; Francois, B.; Diels, M.; Gillis, P. Nutritional value of essential amino acids in the treatment of adults with phenylketonuria. J. Inherit. Metab. Dis. 1995, 18, 127-130. [CrossRef]

27. Lou, H.C.; Toft, P.B.; Andresen, J.; Mikkelsen, I.; Olsen, B.; Guldberg, P.; Guttler, F. Unchanged MRI of myelin in adolescents with PKU supplied with non-phe essential amino acids after dietary relaxation. Acta Paediatr. 1994, 83, 1312-1314. [CrossRef]

28. Schindeler, S.; Ghosh-Jerath, S.; Thompson, S.; Rocca, A.; Joy, P.; Kemp, A.; Rae, C.; Green, K.; Wilcken, B.; Christodoulou, J. The effects of large neutral amino acid supplements in PKU: An MRS and neuropsychological study. Mol. Genet. Metab. 2007, 91, 48-54. [CrossRef]

29. Van Vliet, D.; van der Goot, E.; Bruinenberg, V.M.; van Faassen, M.; de Blaauw, P.; Kema, I.P.; Heiner-Fokkema, M.R.; van der Zee, E.A.; van Spronsen, F.J. Large neutral amino acid supplementation as an alternative to the phenylalanine-restricted diet in adults with phenylketonuria: Evidence from adult Pah-enu2 mice. J. Nutr. Biochem. 2018, 53, 20-27. [CrossRef]

30. Burlina, A.B.; Bonafe, L.; Ferrari, V.; Suppiej, A.; Zacchello, F.; Burlina, A.P. Measurement of neurotransmitter metabolites in the cerebrospinal fluid of phenylketonuric patients under dietary treatment. J. Inherit. Metab. Dis. 2000, 23, 313-316. [CrossRef]

31. Pilotto, A.; Blau, N.; Leks, E.; Schulte, C.; Deuschl, C.; Zipser, C.; Piel, D.; Freisinger, P.; Gramer, G.; Kolker, S.; et al. Cerebrospinal fluid biogenic amines depletion and brain atrophy in adult patients with phenylketonuria. J. Inherit. Metab. Dis. 2019, 42, 398-406. [CrossRef] [PubMed]

32. Bongiovanni, R.; Kirkbride, B.; Newbould, E.; Durkalski, V.; Jaskiw, G.E. Relationships between large neutral amino acid levels in plasma, cerebrospinal fluid, brain microdialysate and brain tissue in the rat. Brain Res. 2010, 1334, 45-57. [CrossRef] [PubMed]

33. Pardridge, W.M.; Oldendorf, W.H. Kinetic analysis of blood-brain barrier transport of amino acids. Biochim. Biophys. Acta 1975, 401, 128-136. [CrossRef]

34. Taslimifar, M.; Buoso, S.; Verrey, F.; Kurtcuoglu, V. Functional polarity of microvascular brain endothelial cells supported by neurovascular unit computational model of large neutral amino acid homeostasis. Front. Physiol. 2018, 9, 171. [CrossRef]

35. Cleary, M.; Trefz, F.; Muntau, A.C.; Feillet, F.; van Spronsen, F.J.; Burlina, A.; Belanger-Quintana, A.; Gizewska, M.; Gasteyger, C.; Bettiol, E.; et al. Fluctuations in phenylalanine concentrations in phenylketonuria: A review of possible relationships with outcomes. Mol. Genet. Metab. 2013, 110, 418-423. [CrossRef] [PubMed] 
36. Taslimifar, M.; Buoso, S.; Verrey, F.; Kurtcuoglu, V. Propagation of plasma L-phenylalanine concentration fluctuations to the neurovascular unit in phenylketonuria: An in silico study. Front. Physiol. 2019, 10, 360. [CrossRef] [PubMed]

37. Surtees, R.; Blau, N. The neurochemistry of phenylketonuria. Eur. J. Pediatr. 2000, 159 (Suppl. 2), S109-S113. [CrossRef]

38. Green, B.; Rahman, Y.; Firman, S.; Adam, S.; Jenkinson, F.; Nicol, C.; Adams, S.; Dawson, C.; Robertson, L.; Dunlop, C.; et al. Improved eating behaviour and nutrient intake in noncompliant patients with phenylketonuria after reintroducing a protein substitute: Observations from a multicentre study. Nutrients 2019, 11, 2035. [CrossRef] article distributed under the terms and conditions of the Creative Commons Attribution (CC BY) license (http://creativecommons.org/licenses/by/4.0/). 